\title{
Necrotic Appendix in Amyand's Hernia: A Case Report
}

\author{
Aybars Ozkan $^{1 *}$, Mesut Okur², Murat Kaya ${ }^{1}$, Adem Kucuk ${ }^{1}$, Ilyas Sari ${ }^{2}$ \\ ${ }^{1}$ Department of Pediatric Surgery, Duzce University Medical School, Duzce, Turkey; ${ }^{2}$ Department of Pediatrics, Duzce University \\ Medical School, Duzce, Turkey. \\ Email: *aybarsozkan@yahoo.com, okurmesut@yahoo.com, murat.kaya@duzce.edu.tr, ademkucuk81@hotmail.com, \\ drilyassari@hotmail.com
}

Received May $7^{\text {th }}$, 2013; revised June $7^{\text {th }}, 2013$; accepted June $20^{\text {th }}, 2013$

Copyright (C) 2013 Aybars Ozkan et al. This is an open access article distributed under the Creative Commons Attribution License, which permits unrestricted use, distribution, and reproduction in any medium, provided the original work is properly cited.

\begin{abstract}
A three-month-old boy was admitted by red, firm, painful swelling in the right groin and vomiting. Surgical repair with appendectomy was performed. We want to emphasize that if the patient has an irreducible strangulated inguinal hernia, appendix or bowel necrosis can be found in the hernia sac.
\end{abstract}

Keywords: Amyand’s Hernia; Necrotic Appendix; Strangulated Inguinal Hernia; Infant

\section{Introduction}

Amyand's hernia is a rare inguinal hernia which occurs when the appendix is included in the hernial sac and becomes incarcerated. Presence of the appendix in the sac complicates the management of inguinal hernias. The appendix may be more predisposed to become vulnerable when contained within a hernial sac, and entering of an appendix into the sac can cause strangulated hernia with necrotic appendix [1]. We present a rare case report with an Amyand's hernia with necrotic appendix.

\section{Case Report}

A three month-old male infant was admitted to the emergency department with a sudden onset six hour-pain together with an irreducible swelling of the right inguinal region. His physical examination revealed a very painful and erythematous lesion, and irreducible swelling in the right inguinal region without abdominal tenderness (Figure 1). There were no other abnormal flags except moderate leukocytosis in routine laboratory evaluation. The plain X-ray abdomen showed multiple air-fluid levels and gas in the right inguinal area and scrotum (Figure 2). Digital rectal examination had no pathological findings. At first, the manual reduction was attempted for the diagnosed case of strangulated inguinal hernia, yet the procedure was not successful. Consequently, an urgent reduction was required in the operating room. Surgical exploration was undergone through a transverse inguinal

*Corresponding author. incision. The inguinal canal was edematous. A necrotic vermiform appendix adhered to the inner surface of the sac was seen on opening the hernia sac, and $6-8 \mathrm{~mL}$ serohemorrhagic fluid drained out (Figure 3). Appendectomy and herniorrhaphy were performed through the inguinal incision at the same time. Congestion, acute inflammation and necrosis were found on histological examination of the appendix. The postoperative recovery was uneventful.

\section{Discussion}

Incarcerated groin hernia is very common among patients who are admitted to the pediatric surgery department. Usually, the small intestine is found in the hernia sac. However, unusual contents may also be encountered such as the ovary, fallopian tube, large bowel, bladder diverticula, Meckel's diverticulum, a part of the small bowel, and presence of vermiform appendix in the hernia sac (Amyand's hernia) [1]. The pathophysiology of Amyand's hernia is still unclear. An appendix in the sac is vulnerable to trauma [2]. In Amyand's hernia with appendicular perforation, the signs of the appendicitis are commonly not seen due to limitation of the inflammation by the hernia sac as in the present case. Therefore, it generally leads to a lower mortality, even though the correct diagnosis is not made preoperatively [3].

The diagnosis of Amyand's hernia is difficult before surgery, usually diagnosed only intraoperatively, due to the clinical presentation regards to an incarcerated hernia, acute hydrocele, acute epididymitis, testicular torsion, 


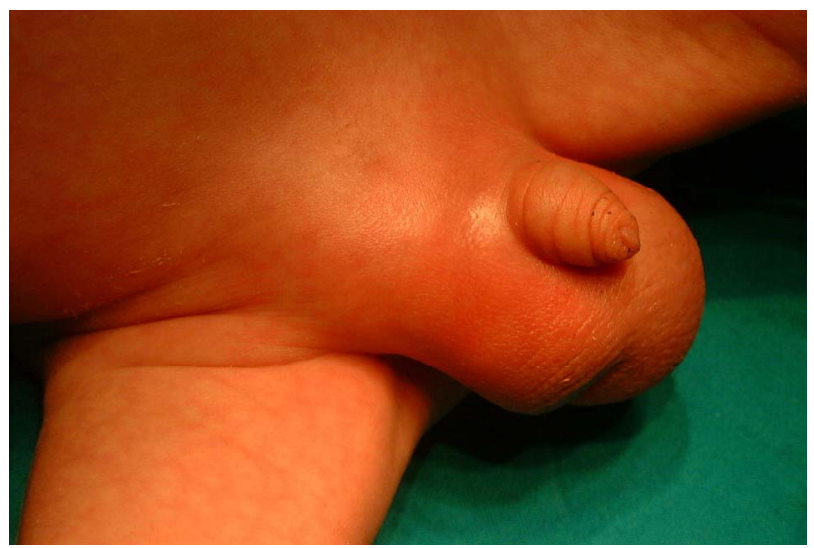

Figure 1. Right inguinal redness and painful swelling with tender scrotum.

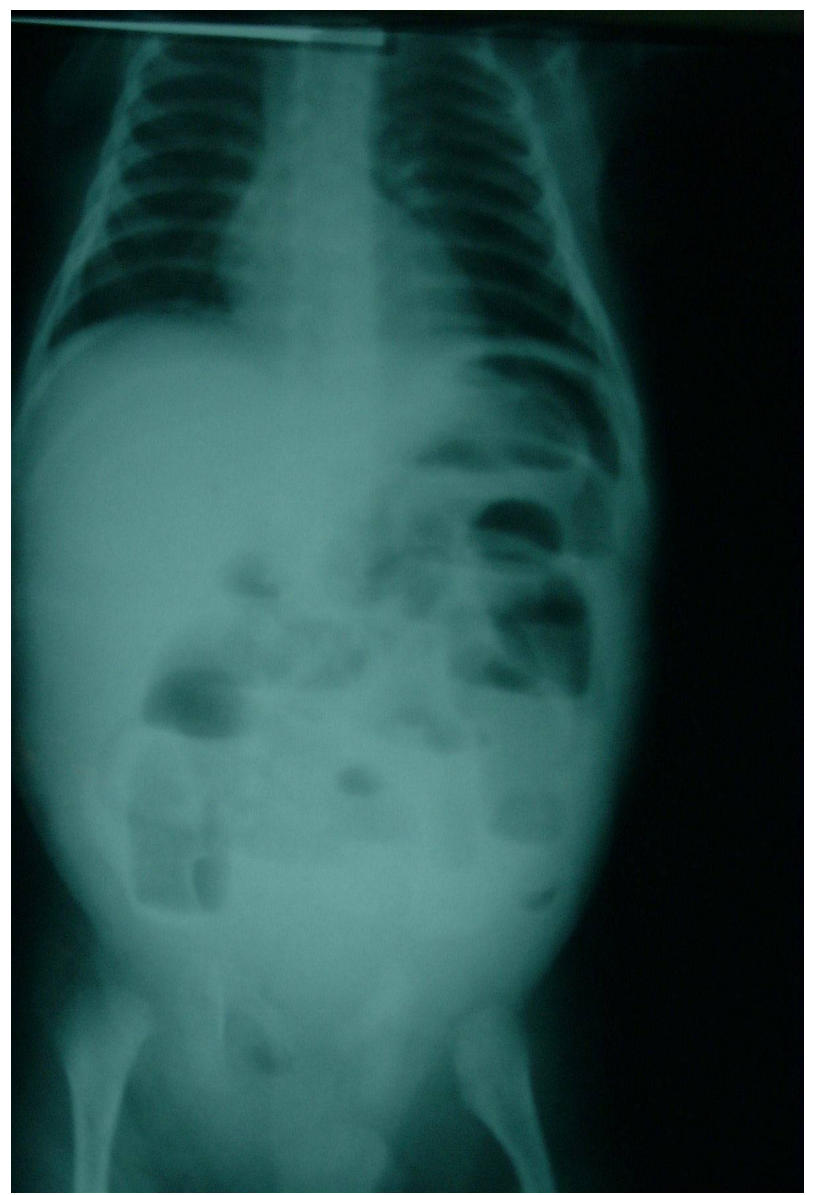

Figure 2. Preoperative supine X-ray. Demonstrating multiple air fluid levels, dilated small bowel loops in the supine film and free air were absent.

Richter's hernia, or inguinal lymphadenitis [4,5]. Nevertheless, there have been cases diagnosed before surgery with ultrasonography and by computed tomography scan [6]. Here, in the present case, an operation was immediately performed because of the strangulated and incarcerated hernia without the need for any imaging process.

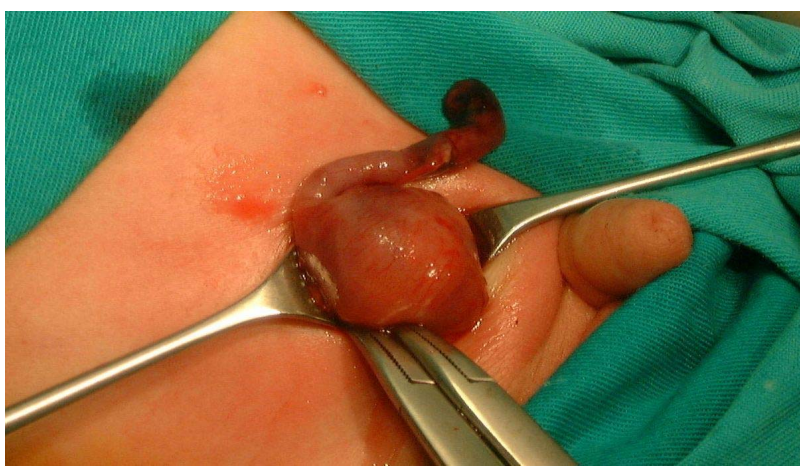

Figure 3. Operative view of Amyand's hernia. After inguinal incision, the necrotic appendix is visible.

The appendix had a necrotic outlook when the hernia sac was opened.

Inguinal incision is usually applied in most of the patients with Amyand's hernia [7]. The selection of surgical intervention depends on whether an inflammation is present. If there is no inflammation in vermiform appendix, an appendectomy is not required in general. If the inflamed vermiform appendix is limited to the hernia sac, appendectomy and hernia repair would be an optimal approach. The presence of peritoneal contamination may require laparotomy $[7,8]$. We have performed appendectomy together with herniorrhaphy through the inguinal incision in the same session since there was no abdominal discomfort. Recently laparoscopic approach is being performed more frequently [9]. It was reported that routine appendectomy was perfromed since wound infections or hernia recurrences in the patients with inguinal hernia containing the appendix was not encountered [10]. Any complications after applied appendectomy and herniorrhaphy were not encountered in the present case, as well. However, it is suggested that early period surgical intervention in irreducible cases, indeed, reduces morbidity of inflammation of the appendix [3].

We want to emphasize that Amyand's hernia should be considered in the differential diagnosis of complicated inguinal hernia. An Amyand's hernia should be suspected in cases with painful swelling of the inguinal region with inflammation of the surrounding connective tissue. Preoperatively, awareness of this condition will be helpful to keep in mind the diagnosis, and preventing delay in intervention.

\section{REFERENCES}

[1] G. S. Doyle and C. McCowan, "Amyand Hernia: A Case of an Unusual Inguinal Herniace," American Journal of Emergency Medicine, Vol. 26, No. 5, 2008, pp. e5-e6. doi:10.1016/j.ajem.2007.10.028

[2] J. Abu-Dalu and I. Urca, "Incarcerated Inguinal Hernia with a Perforated Appendix and Periappendicular Abscess: Report of a Case," Diseases of the Colon \& Rectum, Vol. 
15, No. 6, 1972, pp. 464-465. doi:10.1007/BF02642658

[3] M. N. Srouji and B. E. Buck, "Neonatal Appendicitis: Ischemic Infarction in Incarcerated Inguinal Hernia,” Journal of Pediatric Surgery, Vol. 13, No. 2, 1978, pp. 177179. doi:10.1016/S0022-3468(78)80016-5

[4] R. Kumar, J. K. Mahajan and K. L. Rao, "Perforated Appendix in Hernial sac Mimicking Torsion of Undescended Testis in a Neonate,” Journal of Pediatric Surgery, Vol. 43, No. 4, 2008, pp. e9-e10. doi:10.1016/j.jpedsurg.2007.11.031

[5] S. Turanlı, M. U. Yüksel, Y. Pirhan and A. Çetin, "Inflamed Vermiform Appendix within the sac of Incarcerated Left Inguinal Hernia,” Ulusal Travma ve Acil Cerrahi Dergisi, Vol. 17, No. 5, 2011, pp. 467-469.

[6] Z. V. Maizlin, A. C. Mason, C. Brown and J. A. Brown, "CT Findings of Normal and Inflamed Appendix in Groin Hernia,” Emergency Radiology, Vol. 14, No. 2, 2007, pp. 97-100. doi:10.1007/s10140-007-0601-5
[7] M. A. Kueper, A. Kirschniak, R. Ladurner, F. A. Granderath and A. Konigsrainer, "Incarcerated Recurrent Inguinal Hernia with Covered and Perforated Appendicitis and Periappendicular Abscess: Case Report and Review of the Literature,” Hernia, Vol. 11, No. 2, 2007, pp. 189191. doi:10.1007/s10029-006-0163-6

[8] E. Livaditi, G. Mavridis and G. Christopoulos-Geroulanos, "Amyand's Hernia in Premature Neonates: Report of Two Cases,” Hernia, Vol. 11, No. 6, 2007, pp. 547-549. doi:10.1007/s10029-007-0242-3

[9] J. F. Tycast, A. L. Kumpf, T. L. Schwartz, C. E. Coln, "Amyand's Hernia: A Case Report Describing Laparoscopic Repair in a Pediatric Patient,” Journal of Pediatric Surgery, Vol. 43, No. 11, 2008, pp. 2112-2114. doi:10.1016/j.jpedsurg.2008.07.032

[10] O. P. Ofili, "Simultaneous Appendectomy and Inguinal Herniorrhaphy could be Beneficial,” Ethiopian Medical Journal, Vol. 29, No. 1, 1991, pp. 37-38. 